\title{
Cloud-Based Virtual Organization Framework for Optimizing Corporate Value Chain
}

\author{
Chinedu Paschal Uchenna, Nwankwo Wilson, Olanrewaju Babatunde, Olayinka Comfort \\ College of Natural Sciences, Wellspring University, Benin City, Nigeria
}

\section{Email address:}

drpuchinedu@gmail.com(C.P. Uchenna),wilson.nwankwo@yahoo.com(N. Wilson), bsolanrewaju@gmail.com(O. Babatunde), tcolayinka@gmail.com(O.C. Tosin)

\section{To cite this article:}

Chinedu Paschal Uchenna, Nwankwo Wilson, Olanrewaju Babatunde, Olayinka Comfort. Cloud-Based Virtual Organization Framework for Optimizing Corporate Value Chain. International Journal of Discrete Mathematics. Vol. 3, No. 1, 2018, pp. 11-20.

doi: 10.11648/j.dmath.20180301.12

Received: March 24, 2018; Accepted: April 10, 2018; Published: May 4, 2018

\begin{abstract}
The problems, challenges, and benefits of a Virtual Value Creation (VVC) environment and subsequent deployment of requisite infrastructure to cater for same, save the process of digitization, in an Information Communication Technology (ICT) responsive environment, are all connected to the evolving concept of cloud computing. The uniqueness of every organization affects the virtualization of its ICT and applications. However, provisioning the right cloud computing model to match the strategic and operational goals of such organization is an accepted solution. This paper is aimed at evolving an enhanced model that integrates cloud computing model (CCM) with the VVC Framework of Virtual Organization (VO) to assist the virtual organization stakeholders in reducing the huge capital investment, maintenance, technical personnel, etc. requirements often associated with essential ICT infrastructural setup needs, as well as relieve the top management of technical issues thereby enhancing their focus on core business issues while managing a Virtual organization. VO stakeholders could be afforded the opportunity in the resultant integrated model, the "Cloud Virtual Organization (CVO)", to create better, optimal and customized values in terms of flexibility, cost savings, better scalability, reduced complexity in business processes, increased business focus, advanced technology, better functionality and improved security among others. It is submitted that the foregoing parameters enlisted as features offered by the CVO will immensely propel a Virtual organization towards earning global corporate visibility, competitive advantage, and socio-economic influence in the ever-changing global business environment.
\end{abstract}

Keywords: Virtual Organization, Virtual Value Chain, Value Creation, Cloud Computing, ICT Strategy

\section{Introduction}

Recent innovations in ICT especially Cloud Computing, ECommerce and Virtual Organization (VO), have radically transformed the nature of the global marketplace and how organizations operate and strategize so as to thrive and sustain their competitive edge over rival businesses in the digital marketplace. Virtual organizations that operate on different business model have been on the increase. These organization platforms are enabled by various high performance ICT infrastructure and environment. One of such IT platforms may support these non-traditional businesses is the Cloud IT model. The Cloud Computing Model (CCM) as it is known does not only ensure the integration of core competencies for collaborative ventures among participating enterprises with complementary expertise, but also helps shift focus to their core businesses, bear the huge capital outlay and maintenance costs of the required infrastructure setup and deployment, among other business and security benefits. These help to ensure sustainable global participation, visibility and competitiveness as the organization strives to survive in the ever-changing global economy.

\subsection{Statement of the Problem}

Many organizations face challenges as to how they can establish a global connection or alliance under the backbone of an ICT-intensive infrastructure, especially when the strategic objective is to leverage on the core competencies of other organizations in creating corporate business values. Consequently, business organizations are under pressure to modify their operational and strategic perspectives since the 
gap between e-business model and traditional business model is rapidly disappearing as the forces of the recent economic models become typical of modern business life.

These challenges are essentially contemplated as some of the opportunities behind the evolving cloud technologies and service offerings. As earlier predicted by [1] that "in information societies, the threshold between online and offline will soon disappear, and that once there is no difference, we shall become not cyborgs but rather inforgs, that is, connected informational organisms". Thus, it is clear that the trend in global business operations is going the way of Floridi's prediction. It is in recognition of the changing organizational business trend that this paper presents a discourse on the Cloud-based Virtual Organization (CVO).

\subsection{Objectives}

With existing resources, what an enterprise aims to realizeusually are ways of maximizing shareholder value. In modern times, corporate value has become more important than necessary considering emerging technologies and tough global competition hence every enterprise must adopt the ideology of combining innovative technologies with available resources as the basis for its new line of products and services. In line with the foregoing, the objectives of this paper are:

a. To explore the nature of virtual organizations, its merits and challenges in relation to the cloud computing service delivery model.

b. To examine the concept of Virtual Value Creation (VVC) frameworks in virtual organizations having regard to Hales' model.

c. To explore how shareholder value and wealth creation often expressed in terms of cost-effectiveness, corporate visibility, and competitiveness, etc. in a virtual organization or virtual enterprise can be enhanced through the creation of a cloud-driven virtual business model.

d. To create an optimized corporate value chain model based on Hale's VVC model through the integration of an appropriate cloud-based service delivery component

\subsection{Virtual Organization: Vision and Basis}

Over the last decade, in the theory of corporate organization and strategic management, the term "virtual organization" emerged as a buzzword. Currently, there is no standard definition for it [2]. Greeberg and Heineman [3] have earlier described it as a novel and innovative relationships between organizations and individuals. Bischofberger [4] had regarded a virtual organization as "an efficient, possibly volatile interconnections between enterprises to respond to rapidly changing market conditions supported by information and communication systems and to unify each participant's core competence". He posited that it is safe to state that notable developments in information and communication technology have greatly extended its impact on strategic business decisions despite a deeper scrutiny of the terminology. In addition, the global business environment has turned out to be more and more competitive through dissolving national borders, multinational companies, and definitely, through the Internet which is enabling a global marketplace for information in all conceivable domains. Furthermore, customers demand has become more and more on the increase [4]. Considered with utmost essentiality is how a company responds to its needs and timely delivery of its services since it is believed that a customer is literally only a click away from a competitor. Confronted with these challenges and opportunities, managers are poised to pursue a competitive edge by applying new sophisticated business models which enable them to swiftly and flexibly react [4].

According to [5], the term virtual organization ensued from the phrase "virtual reality", which is itself the process of experiencing reality through the use of multimedia especially audio-visual simulations. Following the "root", it may be safely submitted that virtual organization is meant to simulate a traditional organization (whether or not business-oriented) using information technology platforms especially the Internet. Nevertheless various attempts have been made to express what the term reflects. Agreeably it is a different business model.

Askarzai [6] defines Virtual Organization as a type of temporary or permanent organization with geographically and time-dispersed members (individuals, departments or organizations).

Virtual organization has been further described as "a network of independent firms that join together, often temporarily, to produce a service or product; and often associated with such terms as virtual office, virtual teams, and virtual leadership; the ultimate goal of which is to provide innovative, high-quality products or services instantaneously in response to customer demands"[7]. Hence the strategic goal of a virtual organization is motivated by specific market opportunities, world-class core competence, information networks, interdependent relationships, and permeable boundaries.

\subsubsection{Benefits of Virtual Organizations}

The vision of a Virtual organization is often expressed as a function of its benefits. These benefits are summarized as follows:

a. Access to large customer base usually across the globe.

b. Efficient and save time e.g. time to conduct business process and product development, and marketing are greatly reduced.

c. Great potentials to access financial resources and credits worldwide owing to its non-localization.

d. Access to new markets through partnership with traditional and other virtual organizations.

e. Costs. Risks, and Rewards are shared or distributed across partners.

f. Improved business quality management system: for instance, performance, flexibility, collaboration, marketing, etc. are enhanced.

g. Access to new technology. 
h. Adaptive business model: can adapt to changes in technology.

\subsubsection{Problems of Virtual Organizations}

It is trite to recognize some of the pitfalls and challenges of virtual organizations so as to forge a balance through the introduction of a hybridized model. Karvonen et al. [8] noted that the management of information and its integration over the product life-cycle phases has been the centre of discussion over the past years. It has been submitted that Information adds substantial value to the physical product [8] and that in the virtual organization environment the management of the said information becomes even more challenging and complex when the life-cycle steps involve interoperability among cooperating organizations in which cases there may be evident danger of information losses between [9]. The key challenge in the VO management is still to get the separate entities collaborate towards the aim of the VO [8].

Observing, evaluating, measuring, and assessing the work being done, along with the members' skills, development, and competencies are some of the challenges of virtual teams [9]. It has been submitted that communication as a major challenge of virtual organizations, especially in ascertaining virtual project team management. Hambley et al. [10] posited that coordinating the members of various virtual teams scattered across different time zones has remained the most commonly mentioned challenge for virtual team leaders. In other words, communication which is the fulcrum of every project success presents a recurrent thread among the challenges encountered in virtual program and project management research. "Traditional project environments provide leaders the opportunity to communicate and implement projects with team members located in the same physical geographic location using face-to-face meetings as the primary method of communication [11], but virtual management poses challenges to these traditional methods of communication. In a similar vein, Agarwal [12] identified some of the challenges of Virtual Organization to include the risk of communication flaws that often results in blame game. It is widely believed that if the roles are not properly defined, there is more likelihood of encountering chaos and confusion which ultimately leads to conflicts and project delays. Other notable challenges are effective supervision if the work is not delegated properly; training and development of employees due to inability to identify training needs.

Lee [13] classified the various challenges facing virtual organization into five groups having regard to the scope of the challenge. The groups are: Communications, Cultural teams, Interpersonal, Technological, and Economical. Table 1 presents Lee's classification. Of special interest in this paper are communications, Interpersonal, Technological, and Economic challenges confronting Virtual organizations. To this end, Askarzai et al. [14] concluded that one of the major setbacks of VO is the lack of face-to-face human interaction as against that obtainable in traditional organizations.

Table 1. Challenges of virtual organizations (Source: Lee, 2013)

\begin{tabular}{|c|c|c|c|c|}
\hline Cultural teams & Interpersonal & Technological & Economical & Communications \\
\hline $\begin{array}{l}\text { Context } \\
\text { Difference in work/life philosophies } \\
\text { Cultural differences } \\
\text { Lack of understanding between team } \\
\text { and stakeholders } \\
\text { Shared leadership within the team } \\
\text { Respect for differences among the } \\
\text { team } \\
\text { Team formation }\end{array}$ & $\begin{array}{l}\text { Trust issues } \\
\text { Perceptions } \\
\text { Status confusion } \\
\text { Conflict management } \\
\text { Motivation issues and } \\
\text { disengagement } \\
\text { Relationship building } \\
\text { Personal development }\end{array}$ & $\begin{array}{l}\text { Difficulty in finding } \\
\text { information } \\
\text { Different technological } \\
\text { tools } \\
\text { Integrating information } \\
\text { Shared knowledge bases } \\
\text { IT support } \\
\text { Internet access and } \\
\text { connectivity issues }\end{array}$ & $\begin{array}{l}\text { Setup and equipment costs } \\
\text { Maintenance costs } \\
\text { Difficulties in measuring, } \\
\text { evaluating, and tracking } \\
\text { work } \\
\text { Virtual infrastructure support } \\
\text { within the organization } \\
\text { Missed deadlines, rework }\end{array}$ & $\begin{array}{l}\text { Language barriers } \\
\text { Absence of nonverbal cues } \\
\text { Time zones } \\
\text { Collaboration } \\
\text { Unidirectional communication } \\
\text { Little face-to-face interaction } \\
\text { Lack of multiple } \\
\text { communication approaches }\end{array}$ \\
\hline
\end{tabular}

\subsection{The Concept of Value Creation and Management in Corporate Businesses}

Hale in 2005[15] identified the foundational and functional drivers of value creation. The foundational drivers include: digitization, infrastructure and environment; and represent all advanced ICT elements existing in and out of the enterprise duly provisioned by cloud services such as Infrastructure as a service (IaaS), and Platform as a service (PaaS). On the other hand, the functional drivers include: customized value proposition, strategic sourcing, core competence, and an integrated value net that summarizes the value creation theories and describes how value is created to meet corporate objectives. These drivers constitute the bedrock for sustained competitive strategy in the global marketplace albeit conducted through the SaaS cloud computing delivery. Value creation is promoted by value-based management. Value- based management is the management approach that ensures corporations are run consistently on value i.e. maximizing shareholder value [16]. In other words, value-based management is aimed at the following:

a. Creating value or realistic ways to increase or generate maximum future value often captured in the business strategy of most business enterprises.

b. Managing for value often involving change management, organisational culture, communication, leadership, governance.

c. Valuation or the process of ascertaining the value of the business concern often in terms of its holdings, profitability, and sustainability.

According to [17], Value based management (VBM) is not a methodology but akin to a re-engineering process focusing on all levels of management particularly on corporate culture and organizational behaviour with the ultimate purpose of 
creating and sustaining the corporate value through consistent and continuous performance measurement and valuation.

When VBM is in force in a corporate environment, the organization's management processes provide decision makers at all levels with the right information and incentives to make value-creating decisions. For instance, in a VBM environment, a Business manager will have access to information that will enable him quantify and compare the value of alternative strategies and the incentive to opt for. "Such an incentive is created by specific financial targets set by senior management, by evaluation and compensation systems that reinforce value creation, and-most importantly_by the strategy review process between manager and superiors" [17].

Tang [18] considers VBM as a combination of Value Creation Mindset (value maximization) and Management Processes and Systems that are necessary to translate that mindset into action. Tang has defined "value" in the context of VBM to mean the value of a company which is that determined by its discounted cash flows (DCF). That is, value is created when organizations invest capital at returns that exceed the cost of that capital. He posits that the discounted cash flows is the only metric that takes a longterm view, while still focusing on the balance sheet. This paper considers an integration of value creation mindset, processes and systems as the basis for optimizing the corporate value chain. To create value, the value creator must understand the attractiveness of the market, existing competition, and the competitive position of the company relative to others in the market. Once such understanding is connected to key value chain drivers as identified by [15] competitive strategy can be sustained or modified to maximize future returns. According to [15], the functional drivers of value creation consist of customer value, customization, strategic sourcing, core competence and the integrated value chain. Three foundational drivers provide support for these functional drivers. They are digitization, infrastructure and environment. Jointly, these drivers form a strategic framework which the organization may use to assess its value creation capability. Figure 1 shows the value creation process cycle. It comprises five interrelated phases: identification of the organization's objectives, development of strategies, identification of value drivers, development of actions plans including choosing measures and setting targets, and evaluating performance.

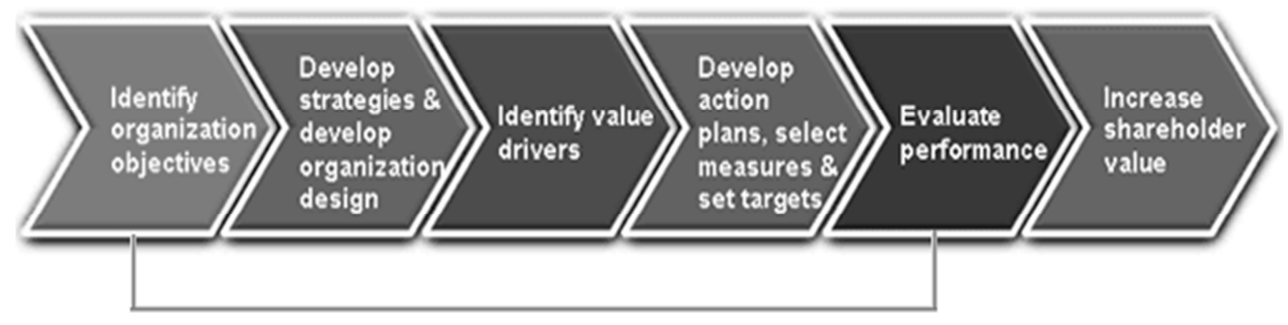

Figure 1. The value creation process.

\subsection{Cloud Computing}

Cloud computing is used to describe both a platform and type of application. A cloud computing platform dynamically provisions, configures, reconfigures, and deprovisions servers as needed. Servers in the cloud can be physical machines or virtual machines. Advanced clouds typically include other computing resources such as storage area networks (SANs), network equipment, firewall and other security devices [19].

Siddiqui [20] described Cloud Computing as nothing but a way for renting the software, platform and/or infrastructure hosted by a provider. The word Cloud indicates that most of the services could be accessed over the Internet. The implication is that that it is the obligation of the Cloud Service Provider to install, maintain, scale, and monitor hardware and/or software services for its customers [20]. In support of the foregoing, [19] had earlier added that cloud computing also describes applications that are accessible through the Internet. These cloud applications use large data centres and powerful servers that host Web applications, Web services, and non-web-based applications. Accordingly, whoever has Internet access and through a web browser can access a cloud application. Cloud computing environments are extensive and support grid computing through provisioning huge interconnected physical and virtual servers on which the grid applications often run. Grid computing was proposed to link and share computing resources [21]. However, cloud computing should not be confused with grid computing. Grid computing involves dividing a large task into many smaller tasks that run in parallel on separate server machines. Grids computing require many computers, typically in thousands, and commonly use servers, desktops, and laptops. Clouds also support non-grid environments, such as a three-tier Web architecture running standard or Web 2.0 applications. The ideology behind the cloud concept is that while providers commit to smarter, faster and cheaper handling of operational activities including parts of information management, their Clients (customers) i.e. Enterprises or Organizations using the cloud services will focus on improving their business processes, increase productivity and innovations. Assuming this is so, significant changes to the existing business processes will likely be required to take advantage of the opportunities that cloud services offer [22].

\subsubsection{Cloud Computing Models and Characteristics}


To understand and appreciate the issues around cloud computing requires a grasp of the three service delivery models it offers. The various services models are often delivered through a contract between the service provider and the customer (client/user). These models also described as delivery models [23] are:

a. Software as a Service (SaaS) where a service provider (SP) delivers software and applications through the internet. The user/customer often subscribes to the software and accesses it through the web or vendor application programming interface (API).

b. Platform as a Service (PaaS), Here, the SP provides on a contractual basis, access to a cloud-based environment (including the underlying infrastructure) on which the clients/customers can build and deliver their independent applications.

c. Infrastructure as a Service (IaaS), where a vendor or provider provides clients pay-as-you-go access to storage, networking, servers and other computing resources in the cloud.

In describing the place of these models, [21] posited that cloud computing is akin to selling " $\mathrm{X}$ as a service". Thus, the following deductions are drawn:

1) IaaS: Infrastructure as a Service $=>$ Selling virtualized hardware.

2) PaaS: Platform as a Service $=>$ selling access to a configurable platform/API.

3) SaaS: Software as a Service $=>$ selling "use of" a software that runs on top of a cloud.

The cloud computing stack in Figure 2 shows the place of these three delivery models. Demonstration of adequate understanding of these three delivery models has significantly shed light on creative ways a few companies had implemented cloud services at different levels. Obviously, organizations could conveniently go virtual or collaborate in virtual organization by leveraging on the any or the entire cloud service provision. Thus rather than concern itself on the huge initial capital outlay and maintenance cost of owing such cloud services, it could allow the cloud service provider provide the needed ICT resource support. With such a provision, the organization can concentrate on its core businesses. In some cases, the said cloud service provider becomes a participating company of the virtual organization.
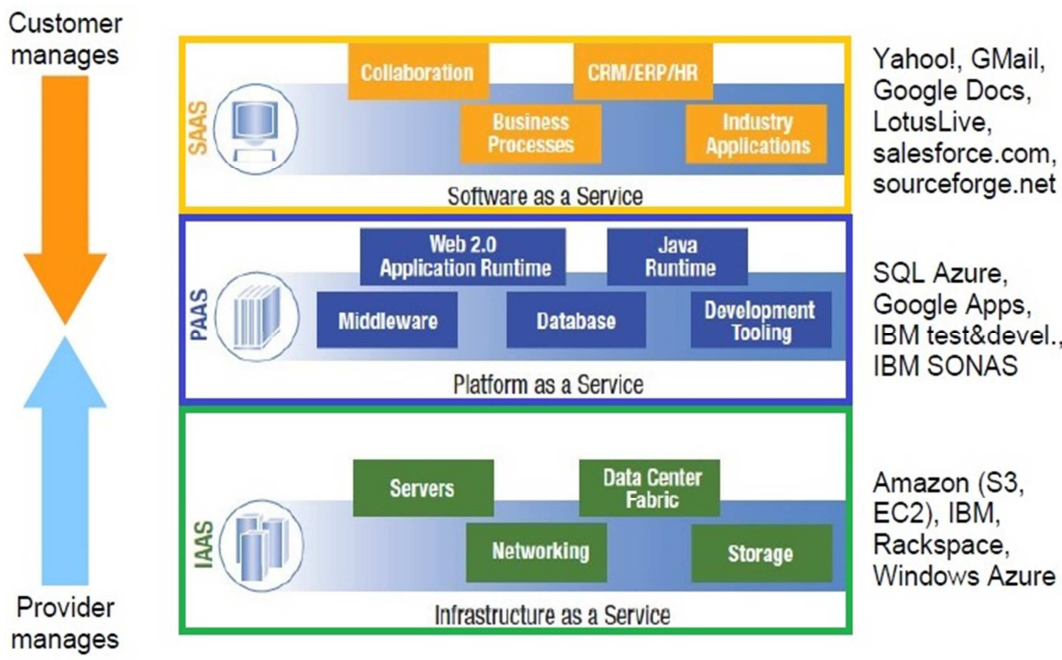

Figure 2. Cloud computing service models (Source: IBM, 2018).

\subsubsection{Benefits of Cloud Computing}

Cloud computing offers a very attractive enticement by promising high financial savings to enterprises. However, cloud's best opportunity is for enterprises to streamline processes and increase innovation by ensuring increasing productivity and transforming business processes through means that were prohibitively expensive before the cloud. The focus of organizations can be streamlined on their core business, rather than raising concerns on scalability of infrastructure. Through cloud computing, resolving peak business demands for performance can be promptly metresulting in more reliable backup, increased scalability, more satisfied customers and even higher margins [22].

Some of the key business benefits offered by the cloud include:

a. Cost Containment: b. Immediacy:

c. Availability:

d. Scalability:

e. Efficiency

f. Resiliency:

g. Software as a subscription

h. Reduced Software Maintenance:

i. Increased Reliability:

j. Environmentally Friendly:

k. Stays Current:

1. Versionless Software:

\subsubsection{The Security Benefits of Cloud Computing}

Imogokate [24] has summarized the advantages of Cloud Computing in relation to security under the following four (4) outlines:

a. Reduced exposure of sensitive data 
b. Simplifies security auditing and testing

c. Enables automated security management

d. Improves redundancy and disaster recovery

In this paper, emphasis is also made on seven technical security benefits some of which are immediate, whereas other progressively evolve as the cloud technology advances. These are:

a. Centralized Data

b. Incident Response/ Forensics

c. Password assurance testing (aka cracking)

d. Logging

e. Improve the state of security software (performance)

f. Secure builds

g. Security Testing

\subsection{Integrated Virtual Value Creation Framework of Virtual Organization}

Organizational practices and previous works on creation of corporate value, indicates the need for an integrated approach that combines already existing conventional theories from strategy, marketing, finance and information systems with new viewpoints that highlights the uncertainty of information resources. The integrated VVC framework answers to the said need. Figure 3 shows a customer-oriented VVC framework that strategically appreciates value creation comprising the customer, and customer value. It depicts the interface between customer value and a customised value proposition, classifying the vital functional and foundational drivers' requirements of value creation. Figure 4 expounds Figure 3. Core elements of business theory in the functional drivers and core elements of IT are integrated in the VVC.

Since the long term existence of any firm is anchored on customer satisfaction and subsequent retention, the VVC framework deliberately maintains customer focus. As against the demand of the short term enterprise goal of creating competitive advantage without customer focus, the long-term goal of developing sustainable competitive advantage requires that customer satisfaction and loyalty are considered as key factors. As Hales [15] rightly asserted, successful value creation is essential for building sustainable competitive advantage and its success directly contributes to the shareholder's valuation of the firm. Hales' concept of VVC combines the concept of new logic of value creation and the development of a model for a virtual value chain. According to the research, value creation at any given stage of the VVC entails a series of five activities: gathering, selecting, organizing, synthesizing and distributing information which in combination with the VVC forms a value matrix that enables enterprises to effectively recognize customers' value and satisfy them more efficiently. Values being a subjective issue depicting customers' perceived value which recognizes the features of a product or service that are the most imperative and thus most extremely valued by the customer. The organization's value proposition need to mirror the set of perceived value requirements of the customer by ensuring full customer participation in the development and production processes, thereby reducing the risk associated with the production of inappropriate products and services. In order to acquire the best pool of resources and competencies strategic sourcing and core competence are necessary. An integrated value chain depends on information to integrate both suppliers and customers into the logistics and transformational processes in order to ensure efficient production and delivery of mass customised. Virtual organization use of ICT to integrate these sources of value creation into a single coherent strategy is the basis of the functional drivers of VVC [15]. Three essential foundational drivers provide needed support to the value creation process. Firstly, digitisation of the firm's value proposition and its transformational processes set limits to the degree to which information can be utilised to create value and gain competitive advantage. Secondly, adequate ICT infrastructure to guarantee the required connectivity with high speed information transmission across the value networks occurring in a timely and secure manner should be in place to facilitate and manage effective capture, storage, and manipulation of information.

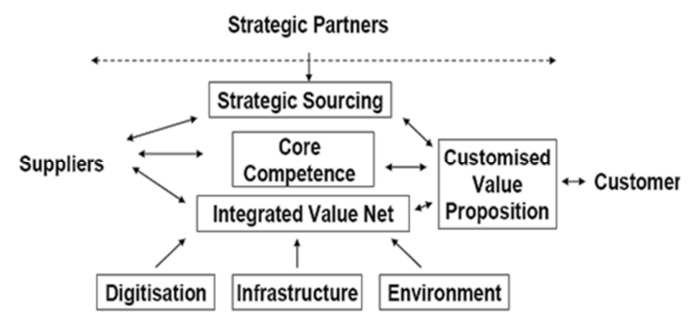

Figure 3. Integrated virtual value creation framework (Hales, 2005).

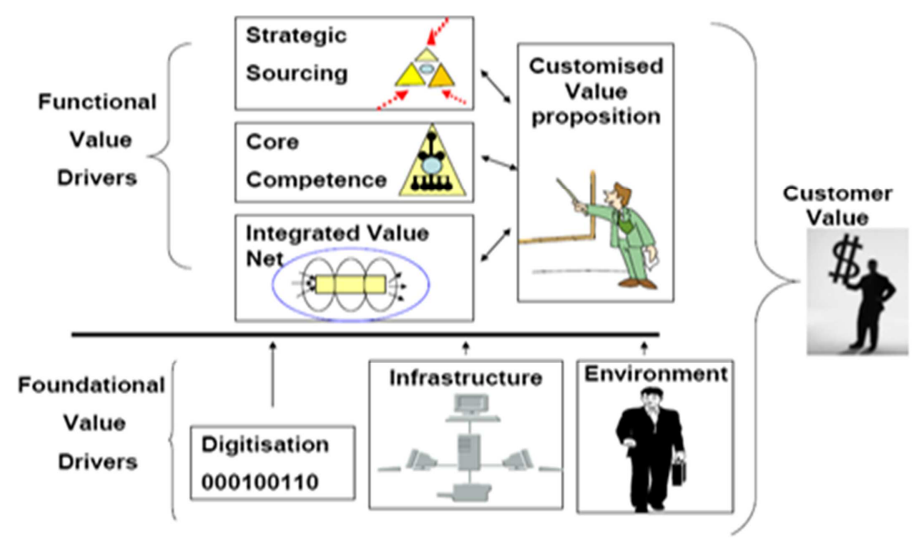

Figure 4. Virtual value creation model (Source: Hales, 2005). 


\section{Method}

This paper follows a sociotechnical approach. The sociotechnical approach considers technology and its effects on the environment. The environment in this context includes persons such as business owners, their partners and customers, as well as the relationships that exist between these entities especially with the involvement of high end technology in driving the operations of the business. The foundation of this sociotechnical study is the Hales VVC model, often regarded as a socio-economic value creation proposition, and how it could be enmeshed with the cloud technology to provide a realistic source of corporate value chain.

First, the strategic role of information systems in realizing organizational competitive strategy and its influence on the corporate strategy are identified through the review of literature on IT-driven business processes particularly businesses run through the virtual organization model. Appreciation of the current impact of the inevitable and everoccurring changes in information on the management of organizational projects further helped to justify how a virtual organization model contribute to value creation for enterprises collaborating or outsourcing projects in the global digital marketplace. Business value drivers such as digitization, infrastructure and environment are emphasized. The functional drivers include a customized value proposition, strategic sourcing, core competence and an integrated value net which summarizes the value creation theories, describes how value are created to meet corporate objectives, and hence sustained competitive strategy for organizations in the global marketplace.

In respect of technology, it is submitted that the cloud computing model presents a more robust, intensive and dynamic environment where ICT resources could be made available to customers, strategic partners, and suppliers (i.e. the functional drivers of the VVC framework of the VO) without huge capital investment for project setup, operationalization and subsequent maintenance. These said ICT resources are to be made available on "pay as you go" bases thereby creating flexibility and lowering running costs since only payment for service is only made while the service is in use and not otherwise. Figure 4 shows a conceptual model representing the interaction between the business environment and technology. According to [25], where the relationship between the organizational concept (VO) and ICT are identified by considering that virtual organizations are service-based socio-technical systems that should be engineered following the cybernetics principles and the economic laws (business objectives, cost, profit) then it would be possible to model a cloud-based framework of virtual organization.

In figure 5, a VVC framework for VO environment is shown to have four components: strategic business partners, suppliers, customers, and an effective information system infrastructure (Cloud model). The first three components are the social business actors. The strategic partners is considered a social business group that manages core competence for collaborative ventures among participating enterprises, promotes knowledge management, and accessibility with effective and efficient use of available resources to satisfy customers and suppliers, creating and maximizing shareholders' wealth and overall corporate value through effective and efficient exploitation of the underlying infrastructure.

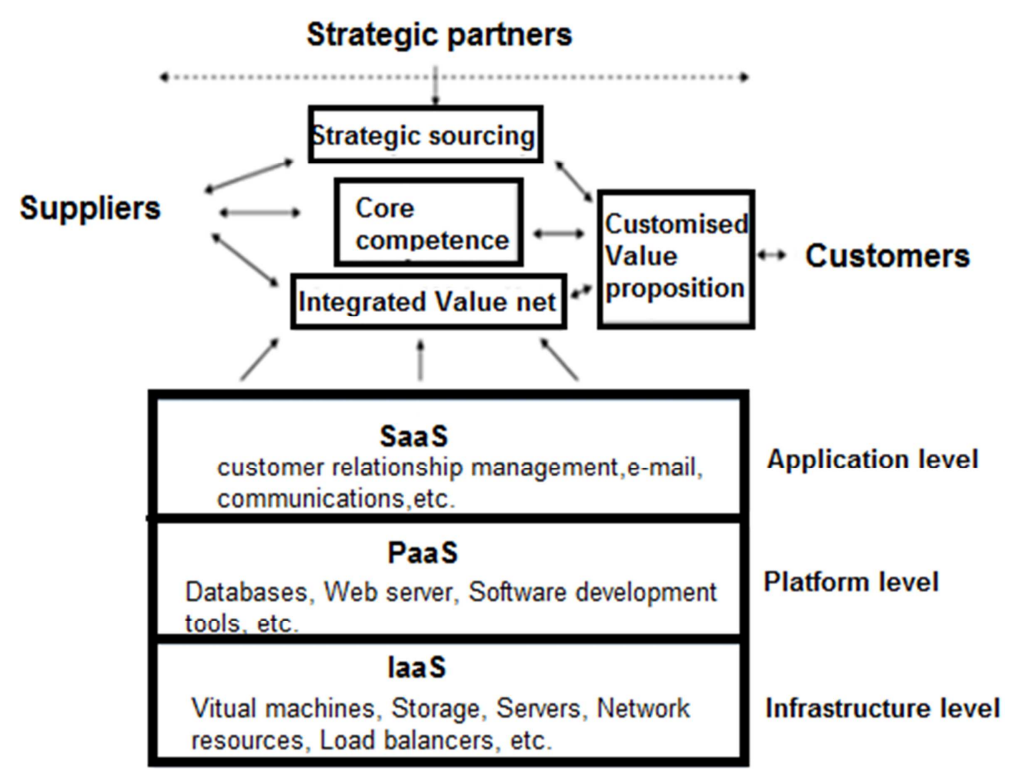

Figure 5. Model of VVC framework of VO in a cloud environment.

\section{Model of Cloud-Based Virtual Organization}

Cloud computing is considered a foundational value driver of VVC Model of VO due to its potential for a more cost effective enabling technology. However, among the three cloud service delivery models, SaaS is the only pure software delivery model that can provide access to business 
functionalities through its direct support for collaboration, business process, customer relationship management, industry applications, etc. remotely usually over the Internet[26]. Thus, it is right to assert that the SaaS cloud service model can provide a cost-effective platform irrespective of the business model. This is line with Cretu's earlier position that the ability of a paradigm shift to avail embedded tools and techniques that assist in capturing common and variable features of various business models within the software at run-time instead of design-time is the essence of the cloud model [25].

Having regard to the foregoing the proposed framework represented in Figure 6 is considered adaptive. The foregoing assertion is evident by considering the present offering of cloud service providers. Today's cloud providers according to Bugiel et al [27] offer both, highly available storage (e.g., Amazon's Elastic Block Store) and massively parallel computing resources (e.g. Amazon's Elastic Compute Cloud (EC2) with High Performance Computing (HPC) Clusters) at relatively low costs. Virtualization implies much flexibility in the foundational drivers of the proposed Cloud VO. This would enable large servers to migrate from one host to another dynamically for load balancing as well as make easier dynamic recovery from hardware failures [28]. Thus VO stakeholders could be assured of safety of all business information and supporting infrastructures throughout the span of the organization in the virtual world. The idea to shift the focus of participating organizations in a virtual cooperation from the maintenance of their infrastructure back to managing their core business as well as releasing smaller organizations from the constraint of investing in a sound infrastructure before their business can kick start under an intensive ICT platform of cloud network cooperation to promote collaboration among various interest groups or stakeholders. With the Cloud, companies can expand their reach into unknown territories. The basic problem of communication, collaboration, and economy as identified by [13] could now be resolved by the introduction of sophisticated cloud services. As a way of attaining and sustaining corporate visibility and competitiveness through the Cloud, organizations are now able to link and integrate, unifying their core competencies to function as a single organization in a virtual world. This implies a change of the rules of the game.
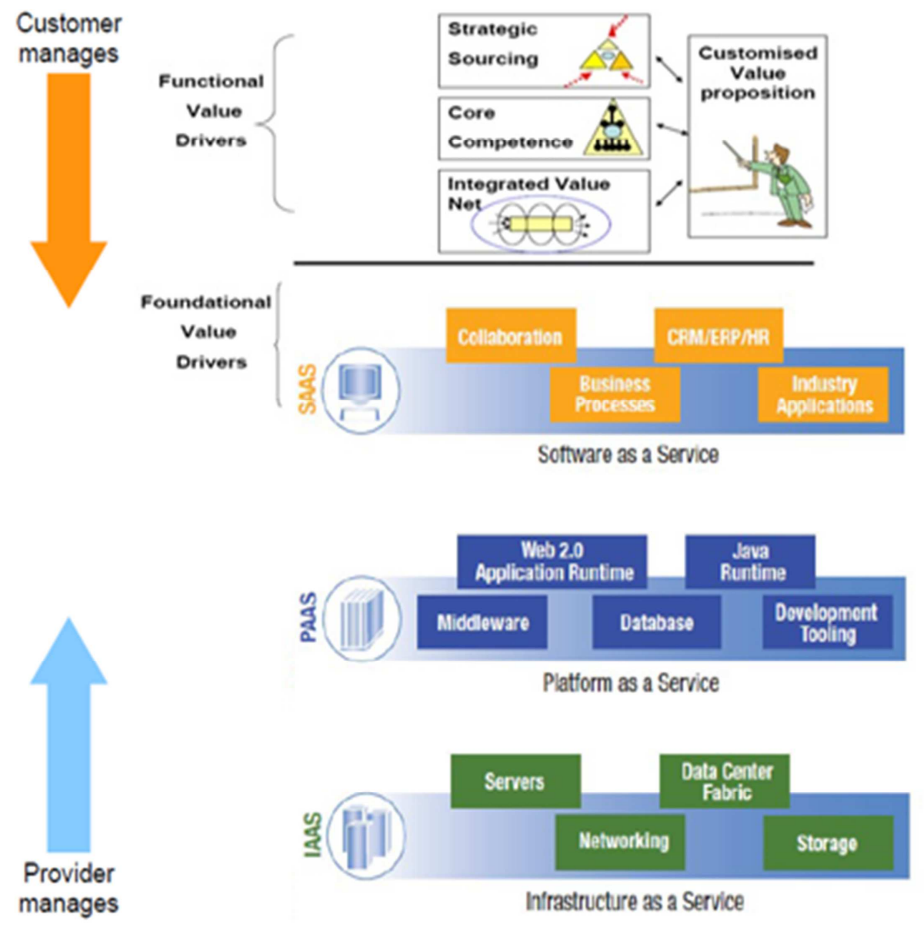

SQL Azure,

Google Apps,
IBM test\&devel.

IBM SONAS

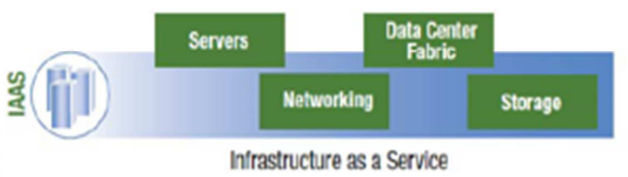

Amazon (S3,

EC2), IBM,

Rackspace,

Windows Azure

Figure 6. Cloud-based virtual organization model.

\section{Discussion}

Cloud computing is evolving as a popular computing paradigm where virtualization and scalability of few available resources are consolidated to provide unlimited services (e.g. computational, storage, networking, etc.) over the Internet. However, as rightly argued in a paper, "the resource capability of a single cloud is generally limited, and some applications often require various cloud centers over
Internet to deliver services together" [28]. This implies that partnering or collaboration in a Virtual Organization will definitely provide great opportunity and strategy to integrate various providers' services with users across multiple autonomous clouds [29]. The framework for cloud-based virtual organization presented in this paper will enable a flexible and dynamic virtual organization management to ensue. One major advantage of driving the virtual organization under the cloud computing especially the public cloud deployment model, is availability, scalability and 
dynamic provisioning enabled through the cloud technologies which readily support all collaborative, projects, business processes, etc.

Therefore, leveraging on these provisions by cloud service providers as the needed virtual organization foundational driver, enable paying for the services in a pay for consumption model. Participating organizations in a Cloud VO model can purchase this services and pay for only what they actually consumed- whether it is hour running a virtual server or actual amount of disk space consumed. With this "pay as you go" concept (usually with prices measured in cent), no long-term commitment to infrastructure (hardware, networks, middleware or software) resources are required.

This paper asserts that Cloud VO is both effective and efficient in creating corporate value (by ensuring more flexibility, cost savings, better scalability, complexity reduction, more business focus, advanced technology, better functionality and improved security) for enterprises in the global digitalized marketplace by measuring the extent to which organizations successfully enable/ facilitate/ permit involvement in the IS strategy of collaboration (or functional VVC drivers integration) both internally or externally under a robust cloud-based ICT platform of virtualization (or foundational VVC drivers integration). Application of framework is diverse and ranges from the enterprise, industry, to public policy making organs such as Government ministries and agencies. Cloud-based virtual organization provides individual users and/or organizations with an innovative framework with which to facilitate own competitive and evolving business environment. Enterprises effortlessly predict business environment in a virtual world by exploring opportunities through public information systems.

Finally, the huge capital investment and maintenance cost requirement in setting up an intense ICT backbone for a virtual private network and the lack of affordable and dependable broadband infrastructure are significant deterrent for establishing and promoting virtual organization systems in remote and many urban areas. Those already operating these forms of ICT networks for business collaboration or virtual organization are experiencing considerable service and network limitations in these areas to leave the cloud as the available, affordable and dependable ICT backbone.

\section{Conclusion}

In practice, as innovations in technology unfold, it is evident that virtual organizations deploying cloud computing environment will increase. At present however, there are not many of such business models when compared to the traditional business models. The reason is simply the lack of dependable security against organizational resources and uncertainties which need to be overcome to warrant virtual value creation (VVC) in the modern business environment. Though many practices in organizations depict some features evident of a Cloud VO, it does not follow they are CVOs.

The main goal of a corporate organization is value creation and value creation must begin with a value creation mindset that interfaces actively with functional and foundational drivers leading to effective and efficient use of the shareholders' finances. Accordingly, the vision of cloud virtual organization is to meet the foregoing goal by improving traditional methods to business; and the extent virtual organizing can contribute strategically, operationally and tactically to corporate value creation is indeed a matter of managerial attitude within the organization, the value chain and industry. Having regard to the various challenges facing virtual organizations including security of transactions and commitments, it is submitted that operating in a secure cloudbased environment is very vital to the strategic success of a VVC especially in the area of corporate visibility, sustained competitiveness, customer satisfaction, shareholder wealth creation and overall stakeholder value creation.

This paper is not envisioned to be a comprehensive examination of all value creation, information systems theories, and IT strategy deployed for effective and efficient virtual organization or collaboration within the cloud. However, it does recognize their contributions and as such incorporates them into a novel and unique framework that can be strategically applied to most enterprises in the everchanging global society.

\section{References}

[1] Floridi, L. (2007) A look into the future impact of ICT on our lives. The Information Society, 23 (1). pp. 59-64.

[2] Afsarmanes, H. and Camarinha, M. (2004). Processes and Foundations for virtual organizations. USA: Kluwer Academic Publisher.

[3] Greenberg, D. and Heneman, R. (2002). Human Resource Management in Virtual Organizations. USA: Information Age Publishing.

[4] Bischofberger, T. (2004). IT-Infrastructure for Dynamic Virtual Enterprises: MSc Thesis, University of Zurich, Switzerland.

[5] The Economist (2009). The virtual organisation. Accessible from http://www.economist.com/node/14301746. Accessed 13 March 2018].

[6] Askarzai, W. (2013). Outline of a Process Model for Virtual Organizations: A Research Perspective, IJBMT, 3(6).

[7] Encyclopaedia of Business management (2018). Virtual Organizations.

[8] Karvonen I., Jansson K., Salkari I., Ollus M. (2004) Challenges in the Management of Virtual Organizations. In: Camarinha-Matos L. M. (eds) Virtual Enterprises and Collaborative Networks. PRO-VE 2004. IFIP International Federation for Information Processing, Vol 149, pp 255-264. Springer, Boston, MA.

[9] Garton, C., and Wegryn, K. (2006). Managing without walls. Lewisville, TX: Mc Press Online, LP.

[10] Hambley, L. A., O'Neill, T., and Kline, T. (2007). Virtual team leadership: Perspectives from the field. International Journal of E-Collaboration, 3(1), pp. 40-63. 
[11] Baladi, I. (2008). An empirical analysis of perceived value of virtual versus traditional project management practice. Dissertation Abstracts International, 68(9), 121.

[12] Agarwal, A. (2012, December 31) Opportunities and challenges of virtual organizations. Project Guru. Available from: https://www.projectguru.in/publications/opportunitiesand-challenges-of-virtual-organizations/

[13] Lee, M. (2013) Challenges of Leading in Virtual Organizations. IT Performance Improvement. Available from http://ittoday.info/ITPerformanceImprovement/Articles/201308Lee.html

[14] Askarzai, W., Lan, Y., \& Unhelkar, B. (2014). Challenges of a Virtual Organisation: Empirical Evidence from Australian SMEs. Global Journal of Finance and Management, 6(9), pp. 919-924.

[15] Hales, K. R. (2005). Value creation in a virtual world. $\mathrm{PhD}$ Thesis, Bond University, Australia.

[16] Value Based Management. Net (2008). What is value based management? Available from $\mathrm{http}: / / \mathrm{www} . v a l u e b a s e d m a n a g e m e n t . n e t / f a q$ what is value ba sed_management.html.

[17] Koller, T., Goedhart, M., \& Wessels, D. (2010). Valuation: Measuring and Managing the Value of Companies. 5th edition. John Wiley \& Sons, Inc., Hoboken, New Jersey.

[18] [18] Tang, D. (2017 March 23). Management \& Leadership: What Is Value Based Management (VBM)? Available from http://flevy.com/blog/what-is-value-based- management-vbm/

[19] Boss, G., Malladi, P., Quan, D., Legregni, L \& Hall, H. (2007). Cloud Computing: High Performance On Demand Solutions (HiPODS). Version 1.0, Available online at http://www.ibm.com/developerworks/websphere/zones/hipods / Accessed: 20 May 2011

[20] Siddiqui, M. (2011). Cloud Computing Security.

[21] Hasan, R. (2011). Security and Privacy in Cloud Computing, en.600.412, Lecture 1, Spring. Johns Hopkins University. Available from http://www.cs.jhu.edu/ ragib/sp11/cs412/lectures/600.412.lect ure01.pptx
[22] ISACA (2009). Cloud Computing: Business Benefits With Security, Governance and Assurance Perspectives Emerging Technology White Paper. Available from http://www.isaca.org/...Center/.../Cloud-Computing- 280ct09Research.pdf

[23] Reilly, D, Wren, C. \& Berry, T. (2011). Cloud Computing: Pros and Cons for Computer Forensic Investigations. International Journal Multimedia and Image Processing (IJMIP), 1(1).

[24] Imogokate (2011, 16 May) Cloud Computing! 4 Security Advantages, 5 Characteristics \& 10 Benefits - A Presentation for Business. Available from http://imogoblog.wordpress.com/2011/05/16/cloudcomputing-4-security-advantages-5-characteristics-10benefits-a-presentation-for-business

[25] Cretu, L. G (2012) Cloud-based Virtual Organization Engineering. Informatica Economica. 16(1). Available fromhttp://www.revistaie.ase.ro/content/61/09\%20$\% 20$ Cretu.pdf

[26] IBM (2018). The Cloud computing Infrastructure. IBM.

[27] Bugiel, S., N"Urnberger, S., Sadeghi, A. \& Schneider, T. (2012). Twin Clouds: An Architecture for Secure Cloud Computing. Available from http://www.techrepublic.com/whitepapers/twin-clouds-anarchitecture-for-secure-cloud-computing/3483635

[28] Jianxin, L., Bo, L., Zongxia, D. \& Linlin, M. (2010). Cloud VO: Building a Secure Virtual Organization for Multiple Clouds Collaboration: 11th ACIS International Conference on Software Engineering, Artificial Intelligence, Networking and Parallel/Distributed Computing London, England. Available from

http://doi.ieeecomputersociety.org/10.1109/SNPD.2010.35

[29] Pan, X., Hamilton, A. F. (2018). Why and how to use virtual reality to study human social interaction: The challenges of exploring a new research landscape. British Journal of Psychology: The Psychological Society. 5 March 2018 Available from https://onlinelibrary.wiley.com/doi/full/10.1111/bjop.12290 [Accessed: March 23, 2018] 